\title{
The Finite Element Simulation Study on Thermal Deformation of Ground Heat Exchange Pipe
}

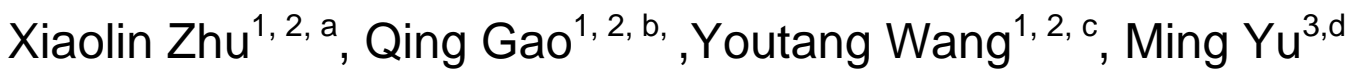 \\ ${ }^{1}$ State Key Lab. of Automotive Simulation and Control, Jilin University, Changchun 130025, China; \\ ${ }^{2}$ Department of Thermal Energy Engineering, Jilin University, Changchun 130025, China; \\ ${ }^{3}$ College of Materials Science and Engineering, Jilin University, Changchun 130025, China \\ azxl_good2005@163.com, bgaoqing@jlu.edu.cn, cwangyoutangk@163.com, dyuming@jlu.edu.cn
}

Keyword: ground heat exchange pipe, thermal deformation, thermal strain, Finite Element method

\begin{abstract}
During long-time operation, thermal deformation of heat exchange pipe weaken the capability and reduce the reliability of heat transfer system, especially the heat exchange pipe with initial bending in high temperature storage condition will make problem more seriously. The finite element simulation study based on ABAQUS code was carried out to explore thermal deformation behavior of heat exchange pipe and interaction between pipe-soil interfaces, through establishing the typical initial bending model of pipe body and the description of the basic equations The distribution law of effective stress, displacement and plastic strain at feature edges and the cross section were obtained. The result showed that value of effective stress, displacement and plastic strain distribution of soil are cyclical fluctuation change with different bending deflection and bending direction, the location of maximum bending deflection is the most serious heat transfer attenuation areas.
\end{abstract}

\section{Introduction}

Ground source heat pump and high temperature energy storage technology were rapid development and application in recent decades, but the gradual performance degradation and even heat transfer failure of ground heat exchange system were emerging, so the reliability have been paid more and more attention by international researchers. Marita Allan [1] proposed the study of thermal stresses, deformations and thermal fractures of backfill material, which would influence the heat transfer. Bourne [2] studied the temperature stress of heat exchanger piles and found that great temperature stress accumulation can lead to heat exchange structural failure. Anna Gabrielsson [3] had monitored the UTES for three years, large vertical settlements appeared in the underground structure after two freeze/thaw cycles, which caused the unexpected buckling of pipe and resulted in a reduced flow in pipe. In Canada, Lenarduzzi Frank [4] announced the problem of vertical ground pipes squeeze in a GSHP project during the first heating season, at the same time, a series of model experiments were conducted to search for the cause of pipe squeeze.

For thermal deformation behavior research of heat exchange pipe in deep underground, it is difficult to carry out experimental study; numerical simulation for our study provides a highly efficient and simple powerful tool. Based on the finite element code, thermal deformation law of heat exchange pipe with typical initial bending was carried out by ABAQUS code as the foundation, interaction between pipe-soil interfaces was further explored by describe and analysis of effective stress, displacement and plastic strain at feature edges and the cross section. For further analyzing heat exchange capacity degradation failure law of heat exchange pipe providing theoretical basis and speeding up underground energy storage and ground source heat pump technology healthy development.

\section{Basic assumptions and control equations.}

Basic assumptions. In order to simplify the problem and facilitates numerical calculation, the calculation based on the following assumptions:

(1) The initial bending of heat exchange pipe is plane bending; 
(2) The material property is isotropic;

(3) Seepage and pore water on the influence of structural stress, strain and temperature is ignored;

(4) Influence of initial stress is ignored.

Basic control equations.

(1) Mohr-Coulomb equation. Mohr-Coulomb constitutive equation is widely applied in geotechnical engineering, so the equation is used for the soil constitutive equation [5]:

$$
f=\left(\sigma_{1}, \sigma_{2}, \sigma_{3}\right)=\frac{1}{2}\left(\sigma_{1}-\sigma_{2}\right)+\frac{1}{2}\left(\sigma_{1}+\sigma_{2}\right) \sin \varphi-c \cos \varphi=0
$$

Where, $\sigma_{1} 、 \sigma_{2} 、 \sigma_{3}$ is the first, second and three principal stress; $c$ is cohesion; $\varphi$ is internal friction angle;

Smooth elliptic function is used for plastic potential surface in ABAQUS [6]:

$$
\begin{gathered}
G=\sqrt{\left(\left.\varepsilon c\right|_{0} \tan \psi\right)^{2}+\left(R_{m w} q\right)^{2}}-p \tan \psi \\
R_{m w}=\frac{4\left(1-e^{2}\right) \cos ^{2} \Theta+(2 e-1)^{2}}{2\left(1-e^{2}\right) \cos \Theta+(2 e-1) \sqrt{4\left(1-e^{2}\right)(\cos \Theta)^{2}+5 e^{2}-4 e}} R_{m c}\left(\frac{\pi}{3}, \varphi\right) \\
R_{m c}=\frac{1}{\sqrt{3} \cos \varphi} \sin \left(\Theta+\frac{\pi}{3}\right)+\frac{1}{3} \cos \left(\Theta+\frac{\pi}{3}\right) \tan \varphi
\end{gathered}
$$

Where, $\psi$ is dilatancy angle; $\left.c\right|_{0}$ is initial cohesive; $\varepsilon$ is eccentricity ratio, the default is 0.1 in ABAQUS; $\Theta$ is polar angle, be defined as $\cos (3 \Theta)=\frac{r^{3}}{q^{3}}, r$ is third deviatoric stress unchan ged $J_{3}, q$ is equivalent deviatoric stress.

(2)Contact element. Contact element using isotropic extended Coulomb friction model, shear stress and normal stress of contact surface function relationship [7]:

$$
\left\{\begin{array}{l}
\tau=k_{s} \omega \\
\tau=\mu p
\end{array} \omega<\omega_{s} \omega \geq \omega_{s}\right.
$$

Where, $\tau$ is shear stress; $p$ is normal stress; $k_{s}$ is shear contact stiffness; $\omega$ is relative displace ment; $\omega_{s}$ is elastic limit relative displacement; $\mu$ is friction coefficient;

\section{Numerical calculation.}

Geometry model and meshing. Heat exchange pipe structure geometry model with initial continuous bending was established, due to the symmetry of the structure, a half model was used to as the calculation area (figure 1). In geometry model meshing, the mesh element include hexahedron (C3D8R) and tetrahedron (C3D4) three dimensional stress element, nearby the area of heat exchange pipe fine grid was meshed to ensure higher calculation accuracy(figure 2).

Boundary conditions and material properties. The contact condition between heat exchange pipe and soil was set up using nonlinear contact stiffness algorithm and contact was set to "hard contact" form[8], friction coefficient is 0.2 .The model plane of symmetry was set to symmetry constraint( $\mathrm{Z}$ direction displacement and rotation angle of $\mathrm{X}, \mathrm{Y}$ direction is 0$)$, The top face and sub-face of model were set to vertical $Y$ direction displacement is 0 , other external surfaces were set to fixed constraint (displacement of X,Y,Z direction were restricted to 0), this is used to simulate a wide range of soil constraint effect. The initial temperature of model is $12^{\circ} \mathrm{C}$, temperature load range is $30 \sim 70^{\circ} \mathrm{C}$ as uniform loading acting on the whole model in the form of steady state heat conduction. The material properties of heat exchange pipe and soil are shown in table 1, 2.

Table1. Material properties of heat exchange pipe

\begin{tabular}{cccccc}
\hline Density/Kg$\cdot \mathrm{m}^{-3}$ & $\begin{array}{c}\text { Specific-heat } \\
/ \mathrm{kJ} \cdot \mathrm{m}^{-3} \cdot \mathrm{K}^{-1}\end{array}$ & $\begin{array}{c}\text { Thermal-coefficient } \\
/ \mathrm{W}^{-1} \cdot \mathrm{m} \cdot \mathrm{K}^{-1}\end{array}$ & $\begin{array}{c}\text { Thermal-expansion } \\
/ \mathrm{m} \cdot \mathrm{K}^{-1}\end{array}$ & $\begin{array}{c}\text { Elastic-modulus } \\
/ \mathrm{MPa}\end{array}$ & $\begin{array}{c}\text { Poisson } \\
\text { ratio }\end{array}$ \\
\hline 950 & 2300 & 0.42 & 0.00025 & 550 & 0.4 \\
\hline
\end{tabular}


Table2. Material properties of soil

\begin{tabular}{ccccccc}
\hline $\begin{array}{c}\text { Density } \\
/ \mathrm{Kg} \cdot \mathrm{m}^{-3}\end{array}$ & $\begin{array}{c}\text { Elastic-modulus } \\
\mathrm{MPa}\end{array}$ & Poisson ratio & Void ratio & $\begin{array}{c}\text { Internal } \\
\text { friction angle }\end{array}$ & Dilation angle & Cohesion $/ \mathrm{KPa}$ \\
\hline 1600 & 10 & 0.3 & 1.5 & 20 & 5 & 15 \\
\hline
\end{tabular}

\section{Analysis.}

Feature line L1 is located in the contact surface of pipe-soil and symmetry plane, pass through $\mathrm{A}, \mathrm{B}$ and $\mathrm{C}$ (Maximum deflection position) from top surface to sub-face (figure1).Displacement (U) and plastic strain $(\varepsilon)$ distribution of soil contact face were dominated by effective stress $(\mathrm{S})$, which is located in Feature line, to evaluate the thermal deformation of pipe-soil contact surface, displacement and plastic strain distribution of soil contact face reflect the state, which soil is squeezed by thermal deformation of heat exchange pipe and the potential of heat conductance gap occur.

As shown in fig.3 5, effective stress value etc of the feature line near top-face and sub-face severely change, because of the influence of boundary constraints. In the $30 \sim 70^{\circ} \mathrm{C}$ temperature conditions, the distribution of effective stress (S) with different bending deflection of heat exchange pipe present fluctuation change at direction of depth(L). At B point, effective stress extremum is appeared, this is because of radial ( $\mathrm{X}$ axis positive direction) maximum component of axial thermal stress and radial thermal stress load on point B together, point $\mathrm{A}$ and $\mathrm{C}$ locate in reverse direction of pipe body bending are subject to the effect of radial thermal stress only. Due to axial dimension far outweigh the radial, axial thermal stress magnify with the increase of temperature load is greater than the increase range of radial thermal stress, so effective stress at point $\mathrm{A}, \mathrm{C}$ increase less than B and present symmetrical distribution.

Regularities of distribution about displacement (U) and plastic strain $(\varepsilon)$ are similar with effective stress (S).As shown in figure 4 5, at the condition of $30^{\circ} \mathrm{C}$, the tiny displacement and plastic strain has been appeared at feature line, with the rise of temperature load displacement and the plastic strain about $\mathrm{B}$ point increase far outweigh point $\mathrm{A}, \mathrm{C}$. When in the $70^{\circ} \mathrm{C}$ condition, the maximum radial displacement on point $\mathrm{B}$ is $4.2 \times 10^{-4} \mathrm{~m}$, plastic strain is 0.0172 .

The fig.6 11 show that displacement and the plastic strain

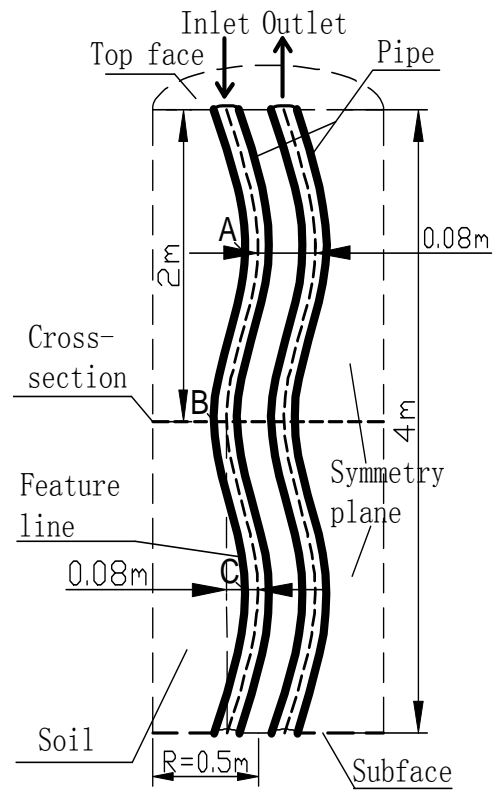

Fig.1 Geometrical model

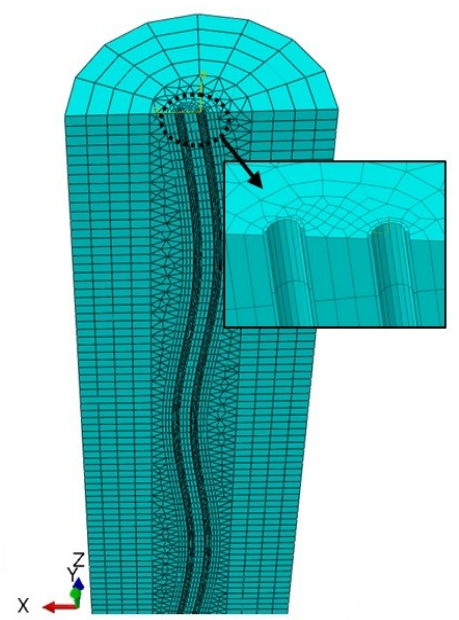

Fig.2 Mesh model distribution of soil cross-sectional in the 30,50 , and $70^{\circ} \mathrm{C}$ temperature condition.

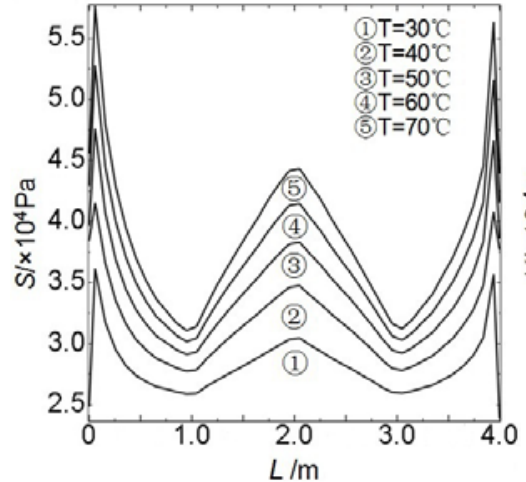

Fig.3 Effective stress

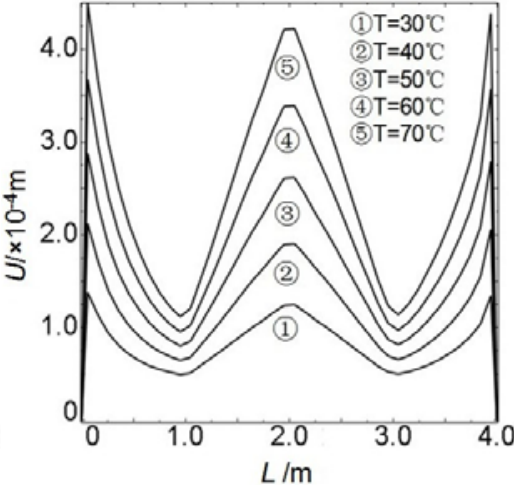

Fig.4 Displacement distribution of $\mathrm{X}$ direction

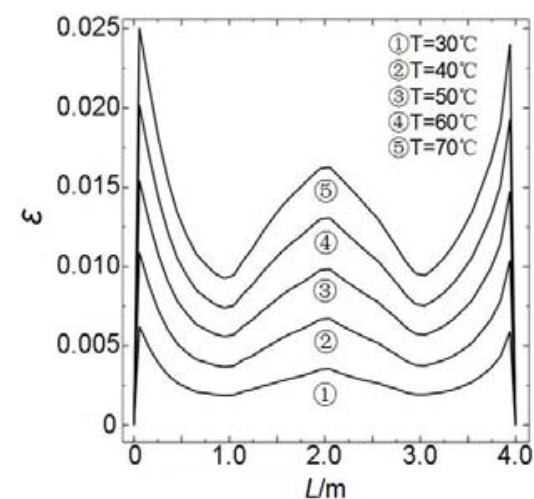

Fig.5 Plastic strain distribution 
The maximum displacement and plastic strain appear at $1 / 2$ perimeter area of pipe left side, this condition decide by the pipe bending direction. The value along the radial decrease gradually and scope of influence gradually expands. When temperature condition is higher than $30^{\circ} \mathrm{C}$, plastic strain area increases between the two pipes. When the temperature load to fall again, heat exchange tube rebound, and plastic area of soil can't rebound, the gap will appear at pipe-soil interface, gap is larger at regional of larger displacements and plastic strain value, eventually lead to possible contact thermal resistance increase.

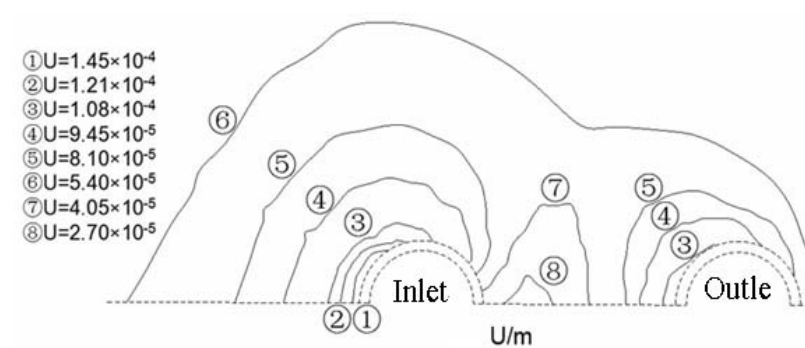

Fig.6 Displacement distribution at cross section $\left(30^{\circ} \mathrm{C}\right)$

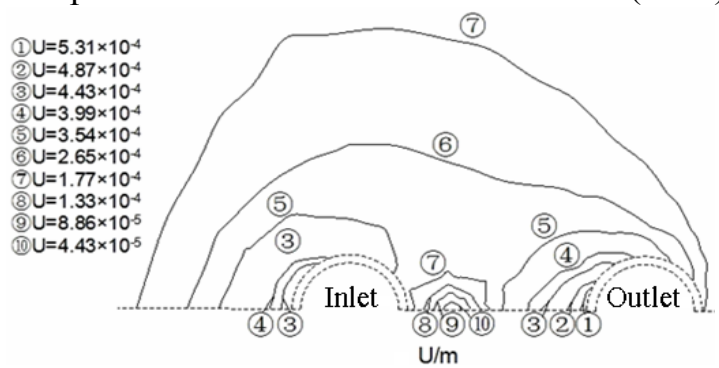

Fig. 8 Displacement distribution at cross $\operatorname{section}\left(70^{\circ} \mathrm{C}\right)$

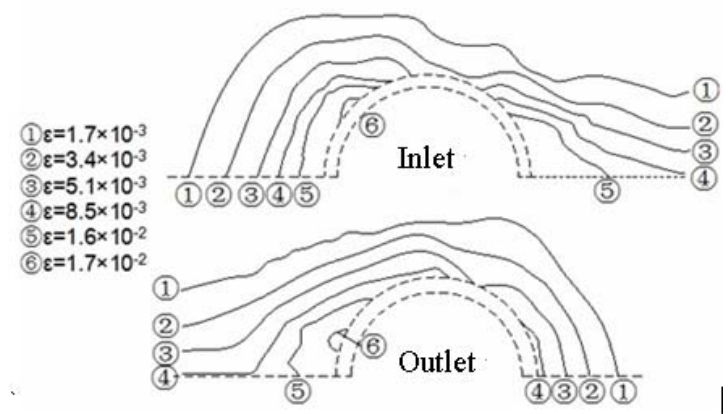

Fig. 10 Plastic strain distribution at cross section $\left(50^{\circ} \mathrm{C}\right)$

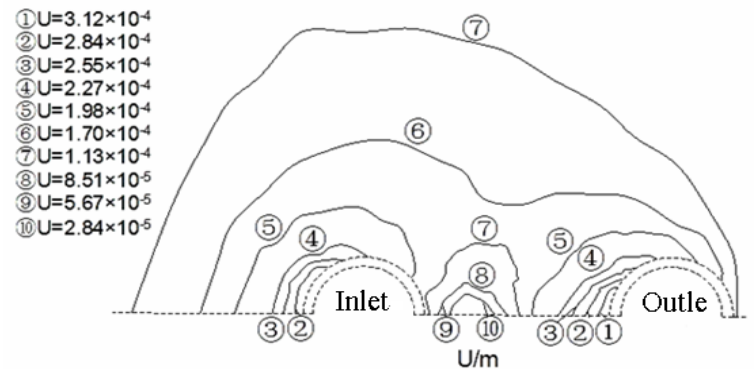

Fig.7 Displacement distribution at cross $\operatorname{section}\left(50^{\circ} \mathrm{C}\right)$

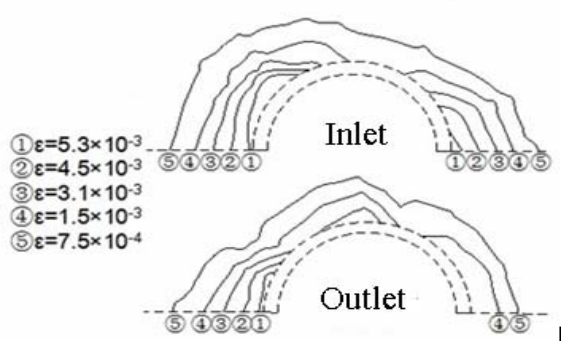

Fig.9 Plastic strain distribution at cross section $\left(30^{\circ} \mathrm{C}\right)$

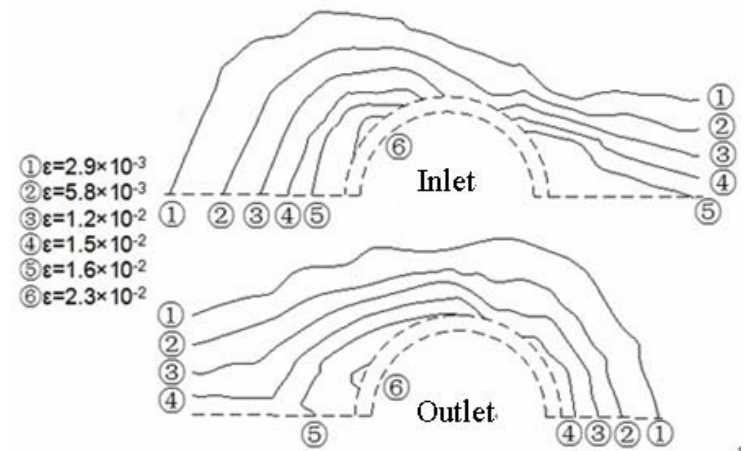

Fig.11 Plastic strain distribution at cross $\operatorname{section}\left(70^{\circ} \mathrm{C}\right)$

\section{Conclusion.}

In the $30 \sim 70^{\circ} \mathrm{C}$ temperature conditions, the distribution of effective stress (S) with different bending deflection of heat exchange pipe present fluctuation change at direction of depth, because of radial ( $\mathrm{X}$ axis positive direction) maximum component of axial thermal stress and radial thermal stress load on position of maximum bending deflection, so the displacement and plastic strain appear at the position. At cross-sectional of soil, the maximum displacement and plastic strain appear at 1/2 perimeter area of pipe left side, this condition decide by the pipe bending direction. The value along the radial decrease gradually and scope of influence gradually expands. These area of deform will lead to possible contact thermal resistance increasing.

\section{References}

[1] Marita Allan. Thermal Conductivity of Cementitious Grouts for Geothermal Heat Pumps: FY 1997 Progress Report.USA Brookhaven National Laboratory, 1997.11. 
[2] Bourne Webb, P. J., Amatya, K., Soga, K., et al. Energy pile test at Lambeth College, London: Geo-technical and thermodynamic aspects of pile response to heat cycles. Geotechnique, 59(3), 237-248, 2009.

[3] Anna Gabrielsson, Marti Lehtmets, Lovisa Moritz, et al. Heat storage in soft clay field tests with heating $\left(70^{\circ} \mathrm{C}\right)$ and freezing of the soil. Report No53, Swedish Geotechnical Institute, 1997.

[4] Lenarduzzi Frank J., Cragg Chris B.H., Radhakrishna H.S..Importance of grouting to enhance the performance of earth energy systems. ASHRAE Transactions, 2000, 106: 424-434.

[5] Zhu Xiangrong,Wang Jinchang.Introduction to partly soil models in ABAQUS Software

and their application to the geotechnical engineering[J].Journal of Rock and Soil Mechanics,2004(25):144-148

[6] Fei Kang,Zhang Jianwei.The application of ABAQUS in geotechnical engineering[M].Beijing: China Water Power Press, 2010

[7] Zhuang Zhuo,etc.Based on ABAQUS finite element analysis and application[M].Beijing:Tsi-nghua University Press,2008

[8] Zhuang Zhuo translation. ABAQUS/standard finite element entry guide [M]. Beijing: Tsinghua university press, 1998 